\title{
HIV Detection in Cuba: \\ Role and Results of the National Laboratory Network
}

\author{
Héctor M. Díaz MD MS PhD, María Teresa Pérez MS, Ana Luisa Lubián MD, Carmen Nibot, Otto Cruz PhD, \\ Eladio Silva MD PhD, Felipe Rolo MD, Maricela Izquierdo MS
}

Timely and accurate detection of HIV infection is critical due to the seriousness of AIDS and its impact on individuals and families, the long symptom-free incubation period, the benefits of enrolling patients as early as possible in therapy and follow-up, and as a pillar of population-based prevention strategies aimed at curbing the epidemic. Thus, an essential component of Cuba's National HIVIAIDS Program (full title, National Program for Prevention and Control of Sexually-Transmitted Diseases and HIVIAIDS) is laboratory diagnosis, $[1,2]$ based on an extensive laboratory network, effective confirmatory algorithms and quality control with external evaluation.

\section{Role of Laboratory Diagnosis in a National HIV Screening Strategy}

The National HIVIAIDS Program was established months after the first AIDS cases were diagnosed in Cuba in 1985. The extremely low HIV prevalence at the time offered a window of opportunity to establish early diagnosis as a central strategy for prevention and containment. Thus, a national screening program was developed for all blood donors, and HIV tests were indicated for vulnerable, at-risk groups including: Cubans returning from international service (among whom the first cases had been diagnosed); pregnant women; contacts of seropositive individuals; persons with other sexually-transmitted diseases; persons who sought testing on their own; patients whose clinical evaluation required ruling out HIV; hospitalized patients, and individuals identified through routine surveillance.[1,2]

From the start, the National Program envisioned incorporation of strong diagnostic capabilities. Accordingly, in 1986, the Ministry of Public Health (MINSAP, its Spanish acronym) established a nationwide laboratory network to provide the necessary technical backbone for national HIV screening. The network, extended throughout Cuba, began providing services for blood banks, Provincial Hygiene and Epidemiology Centers, hospitals and primary care facilities. The number of laboratories in the network rose from 33 in 1986 to 64 a decade later and to 115 by 2009 (Figure 1).

The network required a highly effective diagnostic protocol, assuring both high sensitivity and specificity (MINSAP, National HIVIAIDS Program, Cuba 1985), and diagnostic strategies lacking confirmatory testing were rejected from the start.[2]

Throughout the years, the network's methodology and organization have been guided by a national reference center, the National Retrovirus Diagnostic Reference Center (LNR, its Spanish acronym, located in the AIDS Research
Laboratory, LISIDA), which also carries out the confirmatory testing; procedures developed fully comply with standards set by the national regulatory agency: the Government Center for Drug Quality Control (CECMED, its Spanish acronym);[3] LNR maintains CECMED certification.

\section{Laboratory Diagnosis Strategies \\ to Support the National HIV/AIDS Program}

- Detect HIV infection early

- Provide every person tested with a confirmatory test

- Maintain confidentiality and provide pre- and post-test counseling

- Screen $100 \%$ of blood donations

- Guarantee access to diagnostic testing, with special emphasis on pregnant women

- Facilitate epidemiologic study and provide laboratory support for tracing sexual contacts and following up indeterminate Western blot results

- Support health system in comprehensive care of persons who are seropositive or need further investigation to confirm or rule out seropositivity

Source: MINSAP

\section{Developing an Appropriate Algorithm for the National Laboratory Network}

The diagnostic algorithm displayed in Figure 2 was established on the basis of WHO recommendations and consultation of other expert opinions,[4-7] using tests from various suppliers previously registered for use in Cuba[8] to enable clarification of difficultto-interpret reactivity patterns, follow-up of indeterminate Western blot results for HIV-1, and confirmation of HIV-2 infections.[9]
Figure 1: Cuba's HIV Laboratory Network

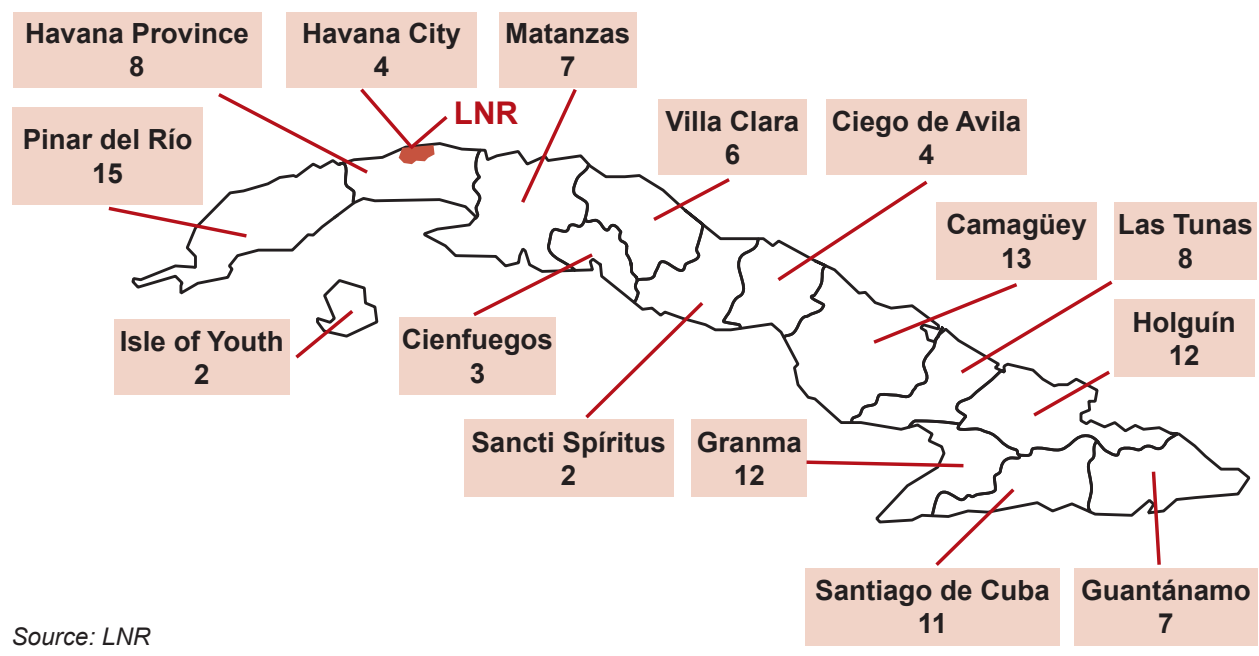


Nevertheless, while the WHO recommends algorithms that do not rely on a single commercial supplier, we have found domestic test production to be an essential pillar of the sustainability of the vital diagnostic capability of the National Program. Some imported tests from reliable suppliers are still used, but most specimens are examined with domestic tests, stabilizing the diagnostic process. These tests include primarily UMELISA' HIV 1+2 RECOMBINANT (TecnoSuma, Cuba)[10] for screening and DAVIH-blot (trademark of the Western blot test used by DAVIH Laboratories, Cuba) for confirmation at LNR.

\section{Figure 2: Diagnostic algorithm for Cuba's National HIVIAIDS} Program

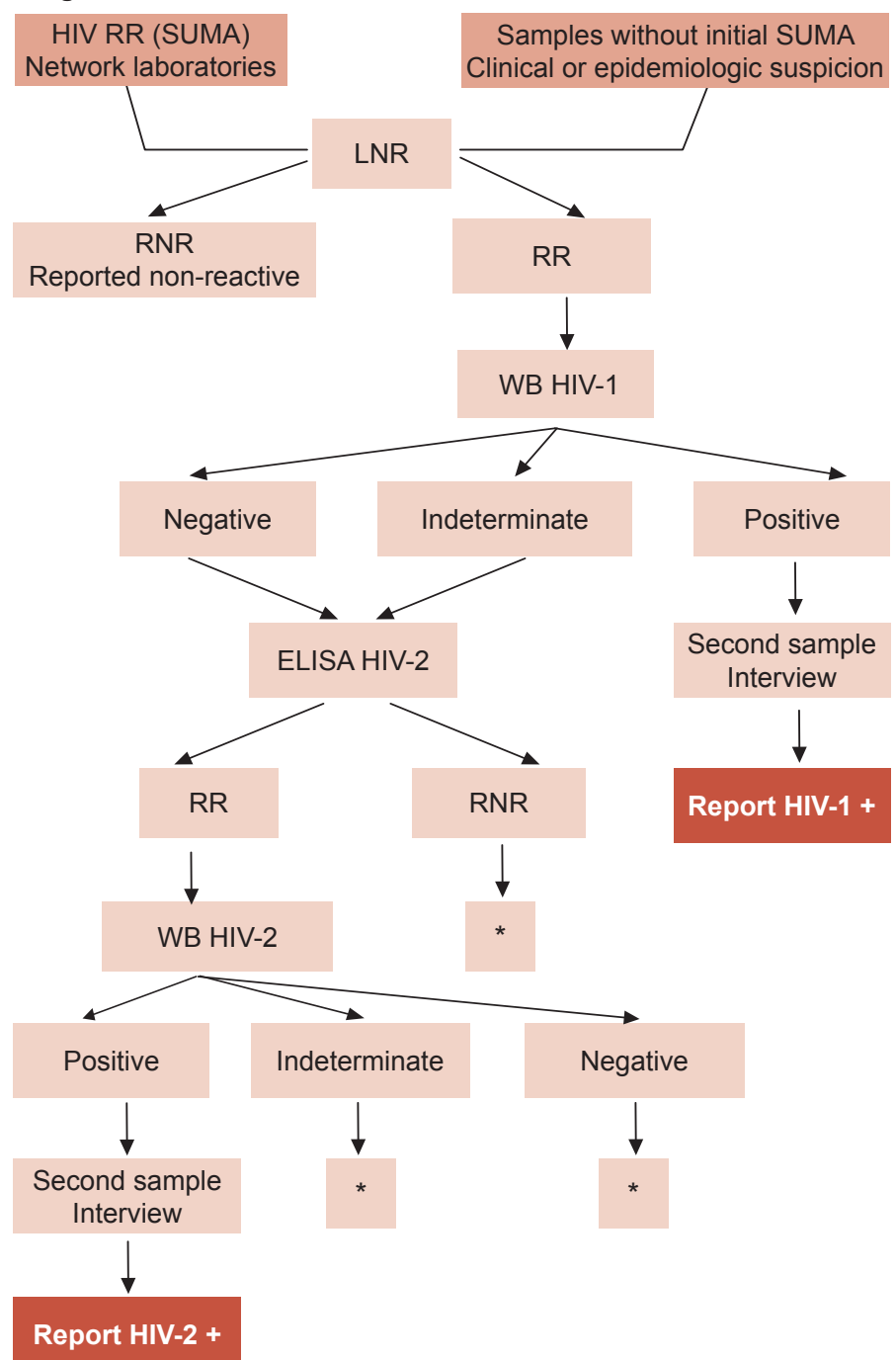

RR: Repeatedly reactive WB: Western Blot

RNR: Repeatedly non-reactive LNR: National Retrovirus Reference Laboratory

SUMA: Ultramicroanalytic system, screening technology developed in Cuba

* If indeterminate, follow-up with infectious disease consultation and assess antigen detection with PCR or culture.

Source: $L N R$

Samples received at LNR from network laboratories are analyzed with a commercial ELISA system with a different principle and antigenic composition than that used for screening.(Vironostika HIV Ag/Ab, Biomériux).[11,12] Repeatedly non-reactive (RNR) samples are reported as negative, while repeatedly reactive (RR) samples are then tested with the DAVIH-blot system, with three possible results: positive, negative, and indeterminate. Positive
DAVIH-blot samples are reported to the National HIVIAIDS Program so that, after counseling and informed consent, a second confirmatory specimen can be taken. Indeterminate or negative results are tested with a commercial ELISA preparation specific to HIV-2 and those that are RR are analyzed with Western blot for HIV-2, which also has the same three possible results: positive, negative and indeterminate. A second sample is also requested from individuals with positive Western blot for HIV-2 (DAVIH-blot HIV-2, DAVIH Laboratories, Cuba). Persons with indeterminate results for any of the Western blot tests remain in serological and epidemiological follow-up for at least one year.[1,3]

While several international organizations require reactivity to only one of the three envelope glycoproteins to define reactivity in Western blot analysis,[7] the Cuban algorithm complies with the WHO criteria, considered the most rigorous.[13] $\mathrm{WHO}$ criteria specify reactivity to at least two viral envelope glycoproteins for a result to be considered positive. A negative result is defined by non-reactivity; any other reactivity pattern not including two envelope glycoproteins is considered indeterminate.[13] We chose these criteria because they are more specific and include careful follow-up of individuals with indeterminate results, allowing us to catch later seroconversion and minimizing false positive diagnoses.

We rejected the WHO option of dispensing with supplementary Western blot testing and instead using one or more different ELISA systems with different principles and antigens depending on specific diagnostic objectives and infection prevalence in the population from which the specimen is taken. The situation in Cuba, with a very low prevalence of HIV infection in the general population and a national program of medical and social attention to all those affected, requires an algorithm with very high specificity, including confirmatory tests to avoid false positives.[14]

Definitive HIV infection diagnosis is made by serologic confirmation with supplementary DAVIH-blot in a second specimen, complemented by epidemiologic criteria for exposure and clinical findings specific to each case.

Infants born to seropositive mothers are followed until age 18 months using a special diagnostic algorithm, including Western blot, PCR detection of maternal viral genetic material and detection of circulating antigens using ELISA for protein $24 \mathrm{Kd}$ (p24) capture.[15,16] PCR and p24 antigen detection are also used in follow-up of persons with indeterminate Western blot results and to clarify samples with difficult-to-interpret reactivity patterns.[1]

\section{Diagnostic Quality Control}

In 1989, LNR's responsibilities were expanded to include evaluation and certification of all diagnostic tests used for screening and confirmation; scientific research mainly aimed at developing new diagnostic tools; and training of personnel for the national laboratory network. It was also charged with establishing a National Program for External Quality Control (PEEC, its Spanish acronym) of network laboratories.

Tests included in the diagnostic algorithm are evaluated according to established regulatory standards,[8] using serum or plasma panel rounds previously characterized by similar sys- 
tems. From 2003 through 2009, 15 serum panel rounds were distributed across the network, with over $80 \%$ laboratory participation and a quality index of $>95 \%$. Sensitivity and specificity of the diagnostics evaluated at that time were $>97 \%$, comparable to internationally accepted results.[17-21]

Simultaneously, registries were designed not only to preserve patient confidentiality, but to ensure traceability of the diagnostic process. Specimen storage and the transport chain from health services to network laboratories and LNR were also strengthened.

PEEC has pinpointed potential vulnerabilities in the functioning of network laboratories, contributed to improving good laboratory practices and to assessing overall performance of the diagnostic component of the National HIV/ AIDS Program. For example, laboratories with poorer performance in the panel rounds were identified and plans developed to assist them to meet quality standards.

\section{Results through 2009}

Table 1 gives an overview of the laboratory network's activity from 1986 through 2009. Over 40 million tests have been performed, with an annual average of nearly 1.7 million. Given that the mean number of new HIV infections detected annually was 509-persons averaging two tests-then the total number of persons screened annually can be estimated at over 1.5 million, or about $13.6 \%$ of the Cuban population. Note that LNR confirmatory testing volume more than doubled between the 2000 through 2004 and 2005 through 2009 periods (mean number of tests annually 17,230 vs. 8181 ), a statistically-significant difference $(p<0.001)$; while increase in the laboratory network's testing volume between the same periods was not statistically significant.

The mean annual number of confirmed positive specimens also increased between the same two five-year periods, from 962 to $2162(p=0.008)$, as did overall proportion of seropositive tests $(12.5 \%$ vs. $11.8 \%, p<0.001)$.

Table 2 shows the number of tests performed, seropositive cases detected, number of tests per case detected, and annual seropositivity rate in the population screened. Cumulatively, a mean of 509 individuals were found HIV-positive annually from 1986 through 2009; however, the mean numbers of new diagnoses annually during the 2000 through 2004 and 2005 through 2009 periods were both statistically significantly greater than the cumulative historical mean (668 and 1238, respectively, $p$ $=0.001$ in both cases) .
Table 2: HIV testing, seropositivity and tests per case detected in Cuba, 1986-2009

\begin{tabular}{|l|r|r|r|r|}
\hline Years & \multicolumn{1}{c|}{ Tests } & $\begin{array}{c}\text { Seropositive } \\
\text { Cases Detected }\end{array}$ & $\begin{array}{c}\text { Tests per Case } \\
\text { Detected }\end{array}$ & $\begin{array}{c}\% \\
\text { Seropositive }\end{array}$ \\
\hline 1986-1999 & \multicolumn{1}{|c|}{$22,935,812$} & 2,686 & 8,539 & 0.011 \\
\hline 2000-2004 & $7,922,553$ & 3,340 & 2,372 & 0.042 \\
\hline 2005-2009 & $9,511,478$ & 6,191 & 1,536 & 0.065 \\
\hline Total & $40,369,843$ & 12,217 & 3,304 & 0.030 \\
\hline
\end{tabular}

Source: LNR

Table 3: Retrovirus infections diagnosed in Cuba, 1986-2009

\begin{tabular}{|l|r|r|}
\hline Years & HIV-1 & HIV-2 \\
\hline 1986-1999 & 2,678 & 8 \\
\hline $2000-2004$ & 3,332 & 8 \\
\hline 2005-2009 & 6,189 & 2 \\
\hline Total & 12,199 & 18 \\
\hline
\end{tabular}

Source: LNR

The mean number of tests done for every seropositive case decreased significantly over time $(p<0.001)$. Nonetheless, despite the rising trend in detection of HIV in specimens received, cumulative population seropositivity by the end of 2009 was still only $0.03 \%$. In 2009 , more than 2 million tests were done, of which $0.071 \%$ were positive.

Annual numbers of HIV-positive persons detected annually are shown in Table 3, differentiated by HIV virus type. Unlike HIV-1, HIV-2 showed a declining trend in new diagnoses, with fewer than one new case annually from 2005 through 2009. This is not statistically significant from the cumulative annual mean ( $0.4 \mathrm{vs}$. 0.75 per year, $p=0.47$ ), not surprising with such small numbers.

Since the increase in confirmatory testing volume at LNR was accompanied by an increase in seropositivity rates in specimens received, we conclude that it was influenced by both increased seroprevalence and active case-finding among groups at risk.

The analysis of seropositivity reported here is by specimens received for confirmation, not by population group, but it is interesting that the data are consistent with epidemiologic reports on HIV prevalence in different study populations in Cuba. Prevalence of HIV-1 in those aged 15 to 49 years was $0.1 \%$ in 2009, among the lowest prevalences in the Caribbean.[22]

Knowing that HIV-2 is less transmissible than HIV-1[23] and that the first HIV-2-positive individuals in Cuba were infected in West Africa[3] does not explain why we have been unable to detect a source or transmission to the most recent individuals diagnosed. Epidemiologic follow-up of their sexual partners would help understand the true HIV-2 situation in Cuba.
Table 1: Testing volume, confirmations and specimen seropositivity, HIV laboratory network and LNR in Cuba, 1986-2009

\begin{tabular}{|l|r|r|r|r|} 
Years & $\begin{array}{c}\text { Tests in the } \\
\text { Network }\end{array}$ & $\begin{array}{c}\text { Reactive specimens } \\
\text { received at } \\
\text { LNR }\end{array}$ & $\begin{array}{c}\text { Specimens } \\
\text { confirmed HIV+ } \\
\text { at LNR }\end{array}$ & $\begin{array}{c}\text { Mean annual } \\
\text { HIV specimen } \\
\text { seropositivity (\%) }\end{array}$ \\
\hline $1986-1999$ & $22,935,812$ & 83,979 & 3,285 & 3.9 \\
\hline $2000-2004$ & $7,922,553$ & 40,908 & 4,813 & 11.8 \\
\hline 2005-2009 & $9,511,478$ & 86,151 & 10,811 & 12.5 \\
\hline Total & $40,369,843$ & 211,038 & 18,909 & 8.5 \\
\hline
\end{tabular}

Source: LNR

\section{Creating Knowledge and Building Laboratory Capacity for the Future}

We are currently evaluating new strategies to decentralize the initial confirmatory process to reduce the number of reactive specimens sent to LNR for definitive diagnosis. Such a strategy requires building greater capacity in regional and provincial laboratories, part and parcel of LNR's ongoing work. Besides its reference function and its roles in quality assessment 
and assurance, and scientific research, LNR also builds human resource capacity through training and continuing education of professional and technical staff in network laboratories. Personnel in the laboratory network include an array of technicians in various biomedical sciences and medical specialists in microbiology and laboratory medicine; it is a highly-qualified workforce that is predominantly female.

The Immunoassay Center (CIE, its Cuban acronym) courses on SUMA technology, offered by TecnoSuma regional centers, are a prerequisite to working in HIV detection and diagnosis. Staff also follow a systematic training program that includes the latest diagnostic techniques, good laboratory practices, and related topics. To this end, LNR has held 11 national workshops, with participation by staff from all network laboratories.

Cuba benefits from a broad network of laboratories providing coverage for blood bank safety, epidemiologic surveillance in vulnerable groups, and services with high social impact, such as early diagnosis in pregnancy, diagnosis of perinatal infection, and anonymous counseling. This strategy helps ensure timely access to medical attention under the National HIVIAIDS Program and to contain the spread of infection within the population. - 1 -

\section{Note on Methods \& Sources}

Data on laboratory testing and findings are from MINSAP's National Statistics Division and the National Retrovirus Diagnostic Reference Center at the AIDS Research Laboratory. A database was created in Microsoft Office Excel 2003; tabulations, epidemiological analysis, and statistical testing, including $Z$ test for independent proportions and $t-$ test for independent means, were done with EPIDAT, version 3.1, 2005 (Xunta de Galicia / HDA, OPS-OMS).[24]

\section{REFERENCES}

1. Ministry of Public Health (CU). Plan Estratégico Nacional ITS/VIH/sida 2001-2006. Resolución No. 110 del Ministerio de Salud Pública [Internet]. Havana: Ministry of Public Health (CU); 2001 Oct [cited 2010 Aug 9]. 82 p. Available from: http://www.sld.cu/galerias/pdf/estrategia. pdf . Spanish.

2. Santín M, Lantero MI, Ochoa R, Joanes J, Pérez JL, González L, et al. Programa Nacional de Prevención y Control de las ITS-VIH-sida. Informe Nacional sobre los progresos realizados en la aplicación del UNGASS. La Habana. República de Cuba [Internet]. Geneva: UNAIDS; 2008 Jan [cited 2010 Aug 9]. 39 p. Available from: http:// data.unaids.org/pub/Report/2008/cuba_2008 country_progress_report_sp_es.pdf. Spanish.

3. Ministry of Public Health (CU). Área de Higiene y Epidemiología. Programa Nacional de Prevención y Control del VIH/SIDA. Havana: Servimpres; 1997. p. 2-3. Spanish.

4. Ministry of Public Health (CU). Regulación No 8. 2001 [Internet]. Havana: Centro para el Control Estatal de los Medicamentos [Government Center for Quality Control of Medicines]; 2001[updated 2010 May; cited 2010 Aug 9]. Available from: http://www.cecmed.sld.cu. Spanish.

5. US. Public health service guidelines for testing and counseling blood and plasma donors for human immunodeficiency virus type 1. MMWR Recomm Rep. 1996 Mar 1;45(RR-2): 1-9.

6. Jackson JB, Balfour HH Jr. Practical diagnostic testing for human immunodeficiency virus. Clin Microbiol Rev. 1988 Jan;1(1):124-38.

7. Constantine NT. HIV Antibody Assays [Internet]. California: Regents of the University of California; c2011. HIV InSite Knowledge Base Chapter May 2006; 2006 May [cited 2007 May 16]; [about 26 p.]. Available from: http://hivinsite.ucsf.edu/ InSite?page=kb-02-02-01

8. CECMED. Regulación 47/2007. Requisitos para la evaluación del desempeño de los diagnosticadores. Ambito Regulador [Internet]. 2007 Jun [cited 2010 Feb 17];8(boletín especial). Available from: http://www.cecmed.sld.cu/Docs/Pubs/AmbReg/2007/AmbReg_SEJun 07.pdf. Spanish.
9. WHO. Global Programme on AIDS. Recomendations for the selection and use of HIV antibody tests. Wkly Epidemiol Rec. 1992 May 15;67(20):145-9.

10. Morales E, Alonso V, Pozo L, González A, Figueiras $Y$, González A, et al. Evaluación de la Aplicación del ensayo UMELISA HIV 1+2 RECOMBINANT en muestras de sangre seca sobre papel de filtro S\&S 903. Rev Biomed. 2004 JulSep;15(3):149-55. Spanish.

11. Schelstraete B, Bijnens BB, Wuyts G. Evaluation of Organon Teknika Vironostika UIV Uni-Form II $\mathrm{Ag} / \mathrm{Ab}$ on the Ortho Summit Processor. J Am Assoc Blood Banks. 1999;39(10 Suppl):74S.

12. Lubián L, Nibot $\mathrm{C}, \mathrm{Az}$ HM, Martin RZ. Comparison of Two Different Generations Assays from Organon Teknika for the HIV Laboratory Diagnosis. 14th International Conference on AIDS; 2002 July 7-12; Barcelone, Spain [CD-ROM]. Italy: Monduzzi Editore International Proceedings Division; 2002. 7 CD-ROM.

13. WHO. Acquired immunodeficiency syndrome (AIDS). Proposed WHO criteria for interpreting results from Western Blot assays for HIV-1, HIV-2, and HTLV-I/HTLV-II. Wkly Epidemiol Rec. 1990 Sep 14;65(37):281-3.

14. Tamashiro H, Fauquex A, Heymann D, Emmanuel J, Sato P, Maskill W. Reducing cost of HIV antibody testing. Lancet.1993 Jul 10;342(8863):87-90.

15. González Núñez I, Dosal Caruso L, Díaz Jidy M, Pérez J. Atención del niño cubano hijo de madres seropositivas al VIH/SIDA. Rev Cubana Med Trop. 1995;47(3):202-8. Spanish.

16. González Núñez I, Díaz Jidy M, Pérez Ávila J. Cuban program for prevention of mother to child HIV/ AIDS transmission. MEDICC Rev. 2001;3:(1-2).

17. UNAIDS. Guidelines for organizing national external quality assessment schemes for HIV serological testing [Internet]. Geneva: World Health Organization; 1996 Jan [cited 2010 Aug 9]. 39 p. Available from: http://www.who.int/diagnostics_ laboratory/quality/en/EQAS96.pdf

18. Jacobson RH. Validación de pruebas serológicas para el diagnóstico de enfermedades infecciosas. Rev Sci Tech Off Int Epiz. 1998:17:507-26.
19. PAHO. Manual de procedimientos de control de calidad para los laboratorios de serología de los bancos de sangre. Washington DC: PanAmerican Health Organization; 1994 Feb. 50 p. Spanish.

20. Andersson S, Thorstensson R, Ramirez KG, Krook A, von Sydow M, Dias F, et al. Comparative evaluation of 14 immunoassays for detection of antibodies to the human T-lymphotropic virus types I and II using panels of sera from Sweden and West Africa. Transfusion. 1999 Aug;39(8):845-51.

21. Argote E, López G. Pautas para evaluar la calidad de los juegos diagnósticos basados en la técnica de ELISA. Rev Cub Cienc Vet. 1995;24(2):16-9. Spanish.

22. UNAIDS. Situación de la epidemia de sida diciembre 2009 [Internet]. Geneva: World Health Organization; 2009 Dec [cited 2010 Aug 9]. 100 p. Available from: http://data.unaids.org/pub/ Report/2009/jc1700_epi_update_2009_es.pdf. Spanish.

23. Kashyap B, Gautam H, Chadha S, Bhalla P. Delayed progression and inefficient transmission of HIV-2. Southeast Asian J Trop Med Public Health. 2010 May;41(3):570-3.

24. Xunta de Galicia, Organización Panamericana de la Salud. Epidat 3.1: análisis epidemiológico de datos tabulados [Internet]. Santiago de Compostela: Xunta de Galicia, OPS; 2006 [cited 2009 Nov 26]. Available from: http://dxsp. sergas.es/ApliEdatos/Epidat/cas/default.asp. Spanish.

\section{THE AUTHORS}

Héctor M. Díaz Torres (Corresponding author: hectorm@infomed.sld.cu), internist with a master's degree in infectious and tropical diseases and a doctorate in medical sciences. Associate researcher, AIDS Research Laboratory, Havana, Cuba. 
Maria Teresa Pérez Guevara, biochemist with a master's degree. Associate researcher, AIDS Research Laboratory, Havana, Cuba.

Ana Luisa Lubián Caballero, physician specializing in epidemiology. Associate researcher, AIDS Research Laboratory, Havana, Cuba.

Carmen Nibot Sánchez, biologist. Associate researcher, AIDS Research Laboratory, Havana, Cuba.
Otto Cruz Sui, biologist with a doctorate in medical sciences. Associate researcher, AIDS Research Laboratory, Havana, Cuba.

Eladio Silva Cabrera, physician specializing in microbiology with a doctorate in veterinary sciences. Senior Researcher, AIDS Research Laboratory, Havana, Cuba.

Felipe Rolo Gómez, physician specializing in microbiology. Associate researcher, AIDS Research Laboratory, Havana, Cuba.
Maricela Izquierdo Márquez, biologist with a master's degree in biochemistry. Associate researcher, AIDS Research Laboratory, Havana, Cuba.

Submitted: August 30, 2010

Approved for publication: March 2, 2011

Disclosures: None 